\title{
Helicobacter pylori: emergence of a Superbug
}

\author{
Amin Talebi Bezmin Abadi* \\ ${ }^{*}$ Correspondence: amin.talebi@modares.ac.ir \\ Edited by: \\ Souha S. Kanj, American University of Beirut Medical Center, Lebanon \\ Reviewed by: \\ Murat Akova, Hacettepe University School of Medicine, Turkey
}

Department of Bacteriology, Faculty of Medical Sciences, Tarbiat Modares University, Tehran, Iran

Keywords: Helicobacter pylori, superbug, infection, treatment, virulence factors

\section{INTRODUCTION}

It has been shown that Helicobacter pylori is highly genetically heterogeneous. A chromosome containing approximately 1,550 genes resulted in a mutant bacterial strain that adversely affects human health. Previously, regarded as a treatable infection, $H$. pylori is becoming harder to eradicate. The unique features in $H$. pylori biology such as high genetic variability, survival in the harsh conditions of the stomach, and special nitrogen metabolisms have triggered general research interest on this persistent infection. Interestingly, the notion "historic taboo" of sterility of the stomach has been changed after the successful H. pylori isolation by Marshall and Warren in 1983 (1). It is quite obvious that $H$. pylori is emerging as an extraordinary microorganism, which deserves careful consideration. Altogether, such particular biological features of $H$. pylori infection led to many queries in the minds of gastroenterologists, microbiologists, and even basic biologists, to spend thousands of hours applying for grants to study $H$. pylori (2). Current knowledge of the $H$. pylori virulence factors particularly after the latest findings in 2012 and 2013 called for new research on $H$. pylori and its clinical aspects (35). It is a general belief that certain $H$. pylori virutypes should be linked to specific gastroduodenal diseases, but recent studies draw an opposite conclusion. Actually, it is rather the treatment for $H$. pylori that is associated with bacterial virulence. The difficulty observed in $H$. pylori therapy is due to unpredictable antibiotic susceptibility results in various regions, unavailability of new effective drugs, and eventually lack of patient compliance during treatment. In brief, providing a new updated definition of $H$. pylori infection represents a shortcoming in gastrointestinal research.
In this article, we propose realistic views on $H$. pylori therapy and virulence according to the latest findings with focus on a new definition of diseases caused by $H$. pylori.

\section{H. PYLORI: OLD BORN BUT NEWLY RECOGNIZED AS A SUPERBUG}

It appears that $H$. pylori knew what to do to become a successful human gastric colonizer and we are just beginning to understand these mechanisms. Hence, it is worthwhile to consider new strategies to win the battle against this rogue microorganism. The $H$. pylori superbug contains unique biological features that enable it to survive safely in harsh environments. While some scientists insist on beneficiary impact of $H$. pylori colonization, others disagree. Nonetheless, current evidence suggests that the pathogenic $H$. pylori phenotype is more prevalent (6). Altogether, dealing with this bacterium (superbug) will be tough and time consuming. There is no doubt that improved therapeutic strategies can only be implemented if we acknowledge $H$. pylori as a superbug.

\section{ANTIBIOTIC THERAPY OF H. PYLORI: DEFEATED STRATEGY?}

Undoubtedly, the emergence of resistant $H$. pylori strains only few years after its discovery by Warren and Marshall was an underestimated event (7-9). Antibiotic therapy was the first choice against $H$. pylori due to the direct association between remission of digestive diseases and successful bacterial eradication. In 1993, due to several observations of $H$. pylori resistant cases, a standard treatment was suggested to provide a well-established therapeutic regimen (10). Standard treatment for $H$. pylori infection involves clarithromycin, metronidazole, or amoxicillin, in conjunction with a proton pump inhibitor (PPI). This approach was originally a promising solution for reported $H$. pylori antibiotic resistance (11). Such a complex combination of drugs to cure the colonized infection has launched extensive efforts to identify an ideal simpler successful therapeutic intervention. Unfortunately, a steady increase in $H$. pylori resistance to clarithromycin, amoxicillin, and especially metronidazole resulted in the diminished use of standard therapy (12). Nevertheless, Zullo et al. suggested a new "sequential therapy" approach against reported treatment failures (13). They proposed using a PPI and amoxicillin for 5 days followed by a PPI with metronidazole and clarithromycin for the next 5 days (13). Despite various recommendations of suggested treatment regimens, an achievement of successful eradication was not possible, and some patients remained H. pylori positive lifelong. Until today, whenever a colonized patient is referred to a gastroenterologist, he/she will be prescribed the common $H$. pylori therapy, an old strategy that needs major reconsideration. In other words, globally increasing antibiotic resistance among $H$. pylori isolates is the best evidence for the necessity of new therapeutic strategies (14-18). Even if antibiotic resistance is not a potential problem, patient compliance can result in lower efficacy of $H$. pylori therapeutic regimens. We need to rethink current treatment strategies regarding this rogue bacterium. Actually, the frequency of resistant strains has now increased. Currently, $H$. pylori antibiotic resistance is much more problematic than 30 years ago. Conversely, the prevalence of $H$. pylori infection compared with 30 years ago is decreasing. More recently, it has been shown that the presence of various genetic elements such as plasmids and phages can explain $H$. pylori's fascinating genetic diversity (19). 
Obviously, such characteristic of $H$. pylori infection call for an extraordinary adopted strategy on how to deal with this bacterium, which we may call a "superbug." Looking back in the literature can show that we have never been confronted with such a complex therapeutic regimen for any bacterial or viral infection, except for Mycobacterium tuberculosis and HIV infection. Considering H. pylori as a superbug can be a starting point to investigate all possible mutations involved in antibiotic resistance in greater details. However, the point mutations in $H$. pylori genome are known to be responsible for antibiotic resistance. In the near future, new non-invasive and industrialized tests can help physicians detect mutations present in each isolated strain. Accordingly, prescription based on the determined mutational profile can increase the chance of successful treatment. Therefore, a better designed antibiotic therapy for $H$. pylori will soon become a reality in clinical practice. During the last decades, several new virulence factors have been characterized; however, we have still not identified one specific $H$. pylori virulence factor that covers the whole disease spectrum $(20,21)$. It is worthwhile mentioning that new rapid sequencing technology is providing accurate information about $H$. pylori genome and in depth gene structure $(4,22,23)$, validating the present hypothesis about the association between $H$. pylori virulence factors and gastroduodenal diseases. As with H. pylori therapy, scientists are facing a new challenge in $H$. pylori virulence factors. At first glance, we are getting close to discovering the real virulence factor for H. pylori, but on the other hand, we should pay attention to the fact that the bacterium harbors a chromosome with more than 1550 genes of which most are not functionally characterized. Remarkably, our current understanding of $H$. pylori virulence factors poses a serious dilemma. There is not enough evidence to use virulence factors as clinically tools. Further work is required to find a relevant virutype to predict diseases outcome. Possibly, by the end of 2014, newer detailed information can ameliorate the current discussed dilemmas in $H$. pylori research. Applying a new definition of $H$. pylori infection as a superbug in human stomach, and placing higher priority on microbehuman interaction research, can provide more useful perspectives. Hopefully, these perspectives will enable researchers to answer frequently asked questions regarding $H$. pylori in the near future.

\section{ACKNOWLEDGMENTS}

The contents of this review article are sole responsibility of the author and necessarily represent personal perspective.

\section{REFERENCES}

1. Marshall BJ, Warren JR. Unidentified curved bacilli in the stomach of patients with gastritis and peptic ulceration. Lancet (1984) 1:1311-5. doi:10.1016/ S0140-6736(84)91816-6

2. Stein M, Ruggiero P, Rappuoli R, Bagnoli F. Helicobacter pylori CagA: from pathogenic mechanisms to its use as an anti-cancer vaccine. Front Immunol (2013) 4:328. doi:10.3389/fimmu.2013. 00328

3. Taghvaei T, Talebi Bezmin Abadi A, Ghasemzadeh A, Naderi BK, Mohabbati Mobarez A. Prevalence of horB gene among the Helicobacter pylori strains isolated from dyspeptic patients: first report from Iran. Intern Emerg Med (2012) 7:505-8. doi:10. 1007/s11739-011-0614-7

4. Yamaoka Y. Pathogenesis of Helicobacter pylorirelated gastroduodenal diseases from molecular epidemiological studies. Gastroenterol Res Pract (2012) 2012:371503. doi:10.1155/2012/371503

5. Talebi Bezmin Abadi A, Mohabbati Mobarez A. High prevalence of Helicobacter pylori hopQ II genotype isolated from Iranian patients with gastroduodenal disorders. J Pathog (2014) 2014:4. doi:10.1155/2014/842469

6. Fock KM, Graham DY, Malfertheiner P. Helicobacter pylori research: historical insights and future directions. Nat Rev Gastroenterol Hepatol (2013) 10:495-500. doi:10.1038/nrgastro.2013.96

7. McNulty CA, Dent J, Wise R. Susceptibility of clinical isolates of Campylobacter pyloridis to 11 antimicrobial agents. Antimicrob Agents Chemother (1985) 28:837-8. doi:10.1128/AAC.28. 6.837

8. Goodwin CS, Marshall BJ, Blincow ED, Wilson DH, Blackbourn S, Phillips M. Prevention of nitroimidazole resistance in Campylobacter pylori by coadministration of colloidal bismuth subcitrate: clinical and in vitro studies. J Clin Pathol (1988) 41:207-10. doi:10.1136/jcp.41.2.207

9. McNulty CA, Dent JC. Susceptibility of clinical isolates of Campylobacter pylori to twenty-one antimicrobial agents. Eur J Clin Microbiol Infect Dis (1988) 7:566-9. doi:10.1007/BF01962617

10. Jaup BH, Norrby A. Low dose, short-term triple therapy for cure of Helicobacter pylori infection and healing of peptic ulcers. Am J Gastroenterol (1995) 90:943-5.

11. Chey WD, Wong BC. American College of Gastroenterology guideline on the management of Helicobacter pylori infection. Am J Gastroenterol (2007) 102:1808-25. doi:10.1111/j.15720241.2007.01393.x

12. Romano M, Cuomo A. Eradication of Helicobacter pylori: a clinical update. MedGenMed (2004) 6:19.

13. Zullo A, Rinaldi V, Winn S, Meddi P, Lionetti R, Hassan C, et al. A new highly effective short-term therapy schedule for Helicobacter pylori eradication. Aliment Pharmacol Ther (2000) 14:715-8. doi:10.1046/j.1365-2036.2000.00766.x
14. Essa AS, Kramer JR, Graham DY, Treiber G. Meta-analysis: four-drug, three-antibiotic, nonbismuth-containing "concomitant therapy" versus triple therapy for Helicobacter pylori eradication. Helicobacter (2009) 14:109-18. doi:10.1111/ j.1523-5378.2009.00671.x

15. Agudo S, Pérez-Pérez G, Alarcón T, López-Brea M. High prevalence of clarithromycin-resistant Helicobacter pylori strains and risk factors associated with resistance in Madrid, Spain. J Clin Microbiol (2010) 48:3703-7. doi:10.1128/JCM.00144-10

16. Wu W, Yang Y, Sun G. Recent insights into antibiotic resistance in Helicobacter pylori eradication. Gastroenterol Res Pract (2012) 2012:8. doi:10.1155/ 2012/723183

17. Graham DY, Lee YC, Wu MS. Rational Helicobacter pylori therapy: evidence-based medicine rather than medicine-based evidence. Clin Gastroenterol Hepatol (2014) 12(177-186):e173. doi:10.1016/j. cgh.2013.05.028

18. Wu JY, Liou JM, Graham DY. Evidence-based recommendations for successful Helicobacter pylori treatment. Expert Rev Gastroenterol Hepatol (2014) 8:21-8. doi:10.1586/17474124.2014.859522

19. Israel DA, Salama N, Krishna U, Rieger UM, Atherton JC, Falkow S, et al. Helicobacter pylori genetic diversity within the gastric niche of a single human host. Proc Natl Acad Sci (2001) 98(25):14625-30. doi:10.1073/pnas.251551698

20. Gomes LI, Rocha GA, Rocha AM, Soares TF, Oliveira CA, Bittencourt PF, et al. Lack of association between Helicobacter pylori infection with dupA-positive strains and gastroduodenal diseases in Brazilian patients. Int J Med Microbiol (2008) 298:223-30. doi:10.1016/j.ijmm.2007.05.006

21. Abadi AT, Mobarez AM, Bonten MJ, Wagenaar JA, Kusters JG. Clinical relevance of the cagA, tnpA and tnpB genes in Helicobacter pylori. BMC Gastroenterol (2014) 14:33. doi:10.1186/1471230X-14-33

22. Talebi Bezmin Abadi A. Helicobacter pylori: a beneficial gastric pathogen? Front Med (2014) 1:26. doi:10.3389/fmed.2014.00026

23. Talebi Bezmin Abadi A. Therapy of Helicobacter pylori: present medley and future prospective. Biomed Res Int (2014) 2014:7. doi:10.1155/2014/ 124607

Conflict of Interest Statement: The author declares that the research was conducted in the absence of any commercial or financial relationships that could be construed as a potential conflict of interest.

Received: 16 July 2014; accepted: 23 September 2014; published online: 14 October 2014.

Citation: Talebi Bezmin Abadi A (2014) Helicobacter pylori: emergence of a Superbug. Front. Med. 1:34. doi: 10.3389/fmed.2014.00034

This article was submitted to Infectious Diseases, a section of the journal Frontiers in Medicine.

Copyright (C) 2014 Talebi Bezmin Abadi. This is an openaccess article distributed under the terms of the Creative Commons Attribution License (CC BY). The use, distribution or reproduction in other forums is permitted, provided the original author(s) or licensor are credited and that the original publication in this journal is cited, in accordance with accepted academic practice. No use, distribution or reproduction is permitted which does not comply with these terms. 